\title{
Creep Behavior in Pure Magnesium at Room Temperature
}

\author{
Tetsuya Matsunaga, Hiromichi Hongo and Masaaki Tabuchi \\ Research Center for Structural Materials, National Institute for Materials Science, Tsukuba 305-0047, Japan
}

\begin{abstract}
Grain refinement is an effective technique to increase the ductility of magnesium $(\mathrm{Mg})$ at room temperature: it engenders higher minimum creep rate and large rupture strain of $>170 \%$ in the sample with grain size $(d)$ of $1.2 \mu \mathrm{m}$. Its creep brings about dislocation absorption and nucleation at grain boundaries, enhancing grain boundary sliding with low apparent activation energy of $65 \mathrm{~kJ} / \mathrm{mol}$, which is only $70 \%$ of that of grain boundary diffusion. Therefore, grain boundary deformation enhances ductility of $\mathrm{Mg}$ at the low homologous temperature of about 0.3 . However, a sample with $d=6.1 \mu \mathrm{m}$ shows low fracture strain that is only one-third of that in the fine-grained sample. Creep resistance increases with increasing grain size, meaning that grain refinement leads to good ductility but low creep resistance at room temperature. [doi:10.2320/matertrans.M2018334]
\end{abstract}

(Received October 19, 2018; Accepted March 25, 2019; Published May 25, 2019)

Keywords: creep, room temperature, pure magnesium, grain-size dependence, temperature dependence

\section{Introduction}

Magnesium $(\mathrm{Mg})$ and its alloys are promising materials for use in the automobile industry because of their light weight and good energy-absorption properties. However, Mg shows unique mechanical behavior because of its hexagonal closepacked structure. For example, the critical resolved shear stresses for the basal, prismatic, and pyramidal slip systems are $3.3,35.7$, and $35.7 \mathrm{MPa},{ }^{1)}$ respectively. Because the von Mises law is not satisfied by basal slip system, $\mathrm{Mg}$ has low ductility at low temperatures.

An important technique for increasing ductility is grain refinement, which engenders superplasticity in $\mathrm{Mg}$ alloys with grain sizes $(d)$ of less than about $10 \mu \mathrm{m}$ at high temperatures. ${ }^{2-4)}$ Mabuchi et al. ${ }^{2)}$ reported that grain boundary diffusion generates large rupture strain at $448-673 \mathrm{~K}$ in $\mathrm{Mg}-9 \mathrm{Al}-1 \mathrm{Zn}$ alloy because the apparent activation energy $(Q)$ equals the value of grain-boundary diffusion $(92$ $\mathrm{kJ} / \mathrm{mol}$ ). ${ }^{5)}$ However, in the present study, fine-grained pure $\mathrm{Mg}$ shows significant creep behavior and large rupture strain of greater than $170 \%$ with $Q=65 \mathrm{~kJ} / \mathrm{mol}$ at room temperature. Moreover, grain refinement decreases strength, which indicates that the creep resistance of $\mathrm{Mg}$ decreases at the temperature. For that reason, the present study specifically examines the creep mechanism and that generating a large strain at low homologous temperature of about 0.3 .

\section{Experimental Procedure}

Commercial pure $\mathrm{Mg}$ with purity of $99.96 \%$ was extruded at $377 \mathrm{~K}, 414 \mathrm{~K}$, and $481 \mathrm{~K}$ to produce samples with $d=$ $1.2 \mu \mathrm{m}, 1.8 \mu \mathrm{m}$, and $6.1 \mu \mathrm{m}$, respectively. Their inverse pole figure (IPF) maps are shown in Fig. 1. Although grains were slightly elongated along the extrusion direction, they can be regarded as equiaxed grains because their aspect ratios were only $1.4,1.0$ and 1.1 for the samples with $d=1.2 \mu \mathrm{m}$, $1.8 \mu \mathrm{m}$, and $6.1 \mu \mathrm{m}$, respectively. Electron back-scattered diffraction (EBSD) analyses showed a few $\{10 \overline{1} 2\}$ twins in the cross sections of the samples with $d=1.8 \mu \mathrm{m}$ and $6.1 \mu \mathrm{m}$ before mechanical test.

After the materials were manufactured into round-bar-type specimens with $15 \mathrm{~mm}$ gauge length and $3 \mathrm{~mm}$ diameter,
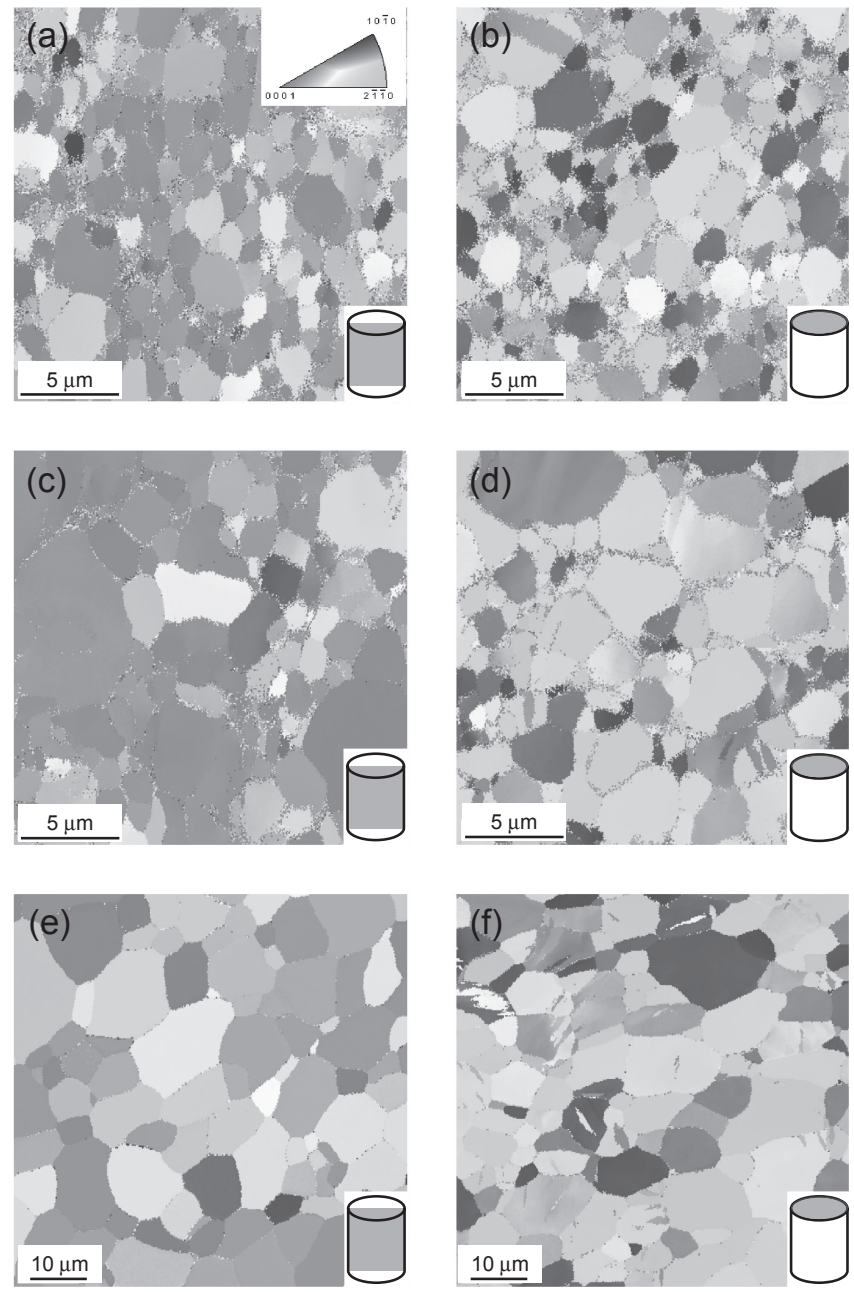

Fig. 1 IPF maps of the samples with $d=(\mathrm{a}, \mathrm{b}) 1.2 \mu \mathrm{m},(\mathrm{c}, \mathrm{d}) 1.8 \mu \mathrm{m}$, and (e, f) $6.1 \mu \mathrm{m}$. (a), (c), and (e) show images of side planes of samples. (b), (d), and (f) show images of cross sections of samples.

creep tests were conducted using dead-load creep frames at $297 \mathrm{~K}$. Conventional tensile tests were conducted using an Instron-type machine at $273 \mathrm{~K}$. The loading direction corresponded to the extrusion direction of the samples. Elongation was measured using strain gauges for tensile tests and linear gauges for creep tests. In this study, nominal stress 
and strain were used for analyses. After the mechanical test, fractography was conducted after creep tests using SEM. Moreover, EBSD analyses were performed after the tests to observe the difference of fracture mechanisms between the fine-grained and the coarse-grained samples. Samples were mechanically ground with waterproof abrasive papers and colloidal silica.

\section{Experimental Results and Discussion}

Figure 2 shows creep rates as a function of strain for the samples with each grain size. Minimum creep rates were observed clearly, even at room temperature. Moreover, the rupture strain increased concomitantly with decreasing grain size and applied stress. Especially, the sample with $d=$ $1.2 \mu \mathrm{m}$ generated large rupture strain of greater than $170 \%$, which is at least three times that of the sample with $d=6.1 \mu \mathrm{m}$. A double logarithmic plot of applied stress and minimum creep rate is presented in Fig. 3. As this figure shows, the finer the grain size becomes, the higher the minimum creep rate becomes. In addition, the stress exponent (n) decreased from ca. 10 to ca. 4 with decreasing grain size. It also shows that creep occurs slowly at low stress in the coarser-grained sample. These results demonstrate that grain refinement decreases strength because of the creep.

To elucidate the creep mechanism, threshold stress $\left(\sigma_{\mathrm{th}}\right)$ was applied for discussion using the Frank-Read source because Kato et al. described that grain boundaries become pinning points toward dislocation motion in fine-grained metals. ${ }^{6}{ }^{6}$ The activation stress of the Frank-Read source is estimated using the following equations.

$$
\begin{aligned}
\tau_{F R} & =\mu b / d \\
\sigma_{F R} & =M \tau_{F R}
\end{aligned}
$$

Therein, $\tau_{\mathrm{FR}}$ represents the activation shear stress of the Frank-Read source, $\mu$ stands for the shear modulus $\{16600 \times[1-0.49 \times(T-300) / 923]\} \mathrm{MPa},{ }^{5)} \quad b$ denotes the magnitude of Burgers vector $\left(3.21 \times 10^{-10} \mathrm{~m}\right),{ }^{5)} \sigma_{\mathrm{FR}}$ expresses the normal stress, and $M$ signifies the Taylor factor of 2.1-4.5. ${ }^{7}$ Using these parameters, $\sigma_{\mathrm{FR}}$ was evaluated as $10-20 \mathrm{MPa}$ for the sample with $d=1.2 \mu \mathrm{m}$. The stress level apparently corresponds to the threshold stress as shown in Fig. 3. The correspondence indicates that the dislocation motion plays an important role in the creep.

Furthermore, it is attempted to discuss with the $Q$ value. Figure 4 shows a double logarithmic plot of applied stress and minimum creep rate at $297 \mathrm{~K}$ or strain rate in tensile tests at $273 \mathrm{~K}$ and $323 \mathrm{~K}^{8}{ }^{8}$ Although the stress exponent slightly increased with increasing temperature, the stress exponents were 3-4 in the conditions. Then, the Arrhenius plot (Fig. 5) of the sample with $d=1.2 \mu \mathrm{m}$ is portrayed at $\sigma / E=2 \times$ $10^{-3}$ in Fig. 4. Because the apparent activation energy was evaluated as $65 \mathrm{~kJ} / \mathrm{mol}$, which is approx. $70 \%$ of that for grain-boundary diffusion, ${ }^{5)}$ conventional diffusion processes were not activated. In the case with the low activation energy, "slip-induced grain-boundary sliding" might be activated by dislocation absorption, for which the activation energy was reported as about $20 \mathrm{~kJ} / \mathrm{mol}$ for AZ31. ${ }^{9)}$ However, the generation of dislocations from the grain boundary is necessary to maintain strain compatibility and the large
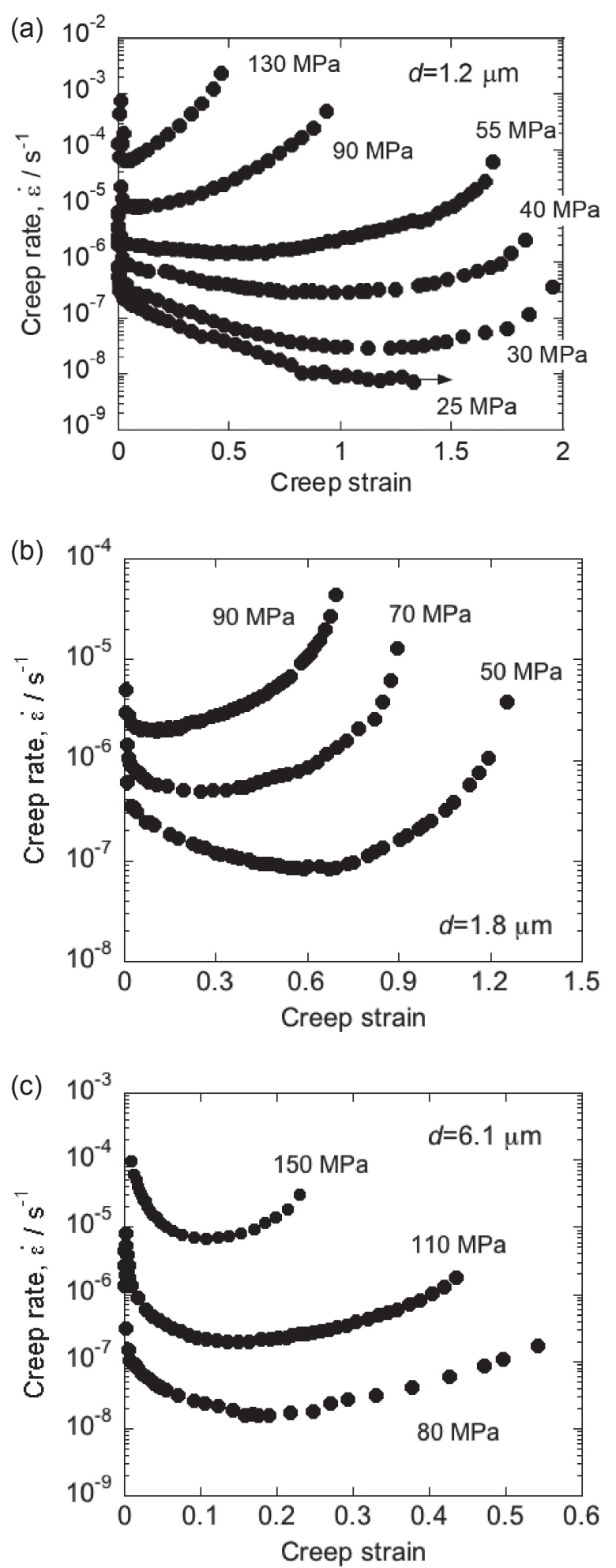

Fig. 2 Creep rate as a function of strain for the samples with $d=$ (a) $1.2 \mu \mathrm{m}$, (b) $1.8 \mu \mathrm{m}$, and (c) $6.1 \mu \mathrm{m}$ at room temperature. The arrow indicates the ongoing test. The elapsed time is about $31000 \mathrm{~h}$.

amount of rupture strain, as proposed by Ball and Hutchinson. ${ }^{10)}$ Zhu et al. calculated the activation energy for dislocation nucleation from the grain boundary as about $0.1 \mathrm{eV}-0.6 \mathrm{eV}$ (from ca. $10 \mathrm{~kJ} / \mathrm{mol}$ to ca. $60 \mathrm{~kJ} / \mathrm{mol}$ ). ${ }^{11)}$ The latter value, which is related to dislocation nucleation at the side surface of the boundary, is almost equal to the $Q$ value found in this study. Generally speaking, dislocations might be dissociated at the grain boundary: one dislocation is absorbed 


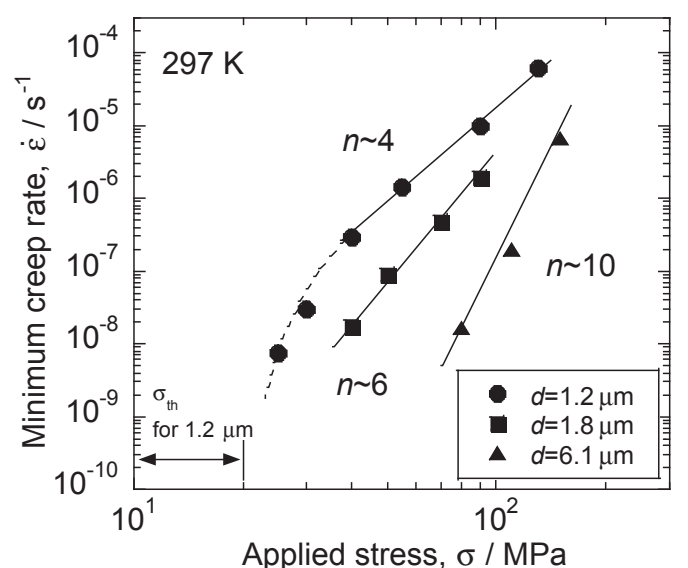

Fig. 3 Double logarithmic plot of the applied stress and minimum creep rate of all samples at $297 \mathrm{~K}$. The stress exponent decreases from ca. 10 to ca. 4 with decreasing grain size.

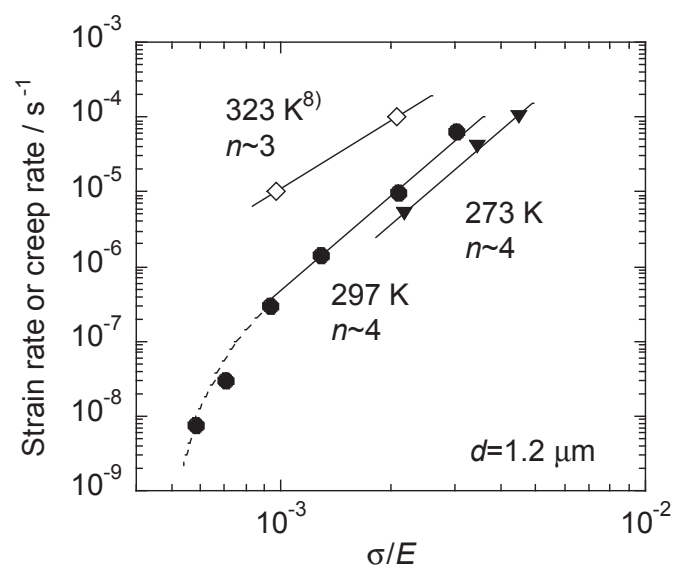

Fig. 4 Double logarithmic plot of the modulus-compensated applied stress and minimum creep rate at $297 \mathrm{~K}$ and strain rate at $273 \mathrm{~K}$ and $323 \mathrm{~K}^{8)}$ for samples with $d=1.2 \mu \mathrm{m}$. The stress exponent is evaluated as $3-4$ in the conditions.

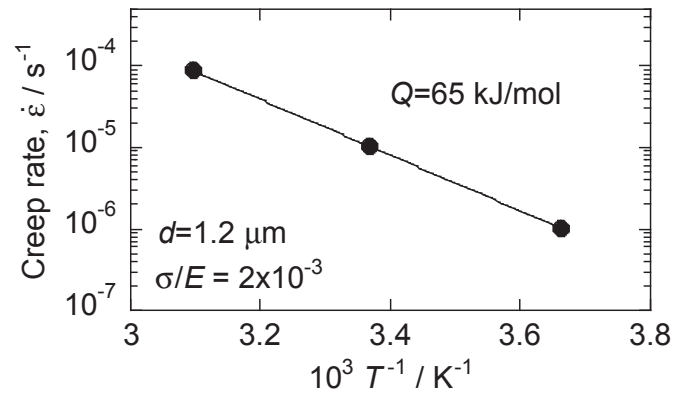

Fig. 5 Arrhenius plot of the sample with $d=1.2 \mu \mathrm{m}$ at $\sigma / E=2 \times 10^{-3}$ between 273 and $323 \mathrm{~K}$. The apparent activation energy is $65 \mathrm{~kJ} / \mathrm{mol}$, which is only $70 \%$ of that of grain boundary diffusion.

into a grain boundary to become a grain boundary dislocation; then another dislocation propagates into an adjacent grain. Therefore, large rupture strain greater than $170 \%$ was generated in the fine-grained sample by intragranular and intergranular dislocation motions.

Finally, the grain size effect on the fracture strain can be discussed. Fracture strain in the sample with $d=6.1 \mu \mathrm{m}$ was about one-third of that in the sample with $d=1.2 \mu \mathrm{m}$,

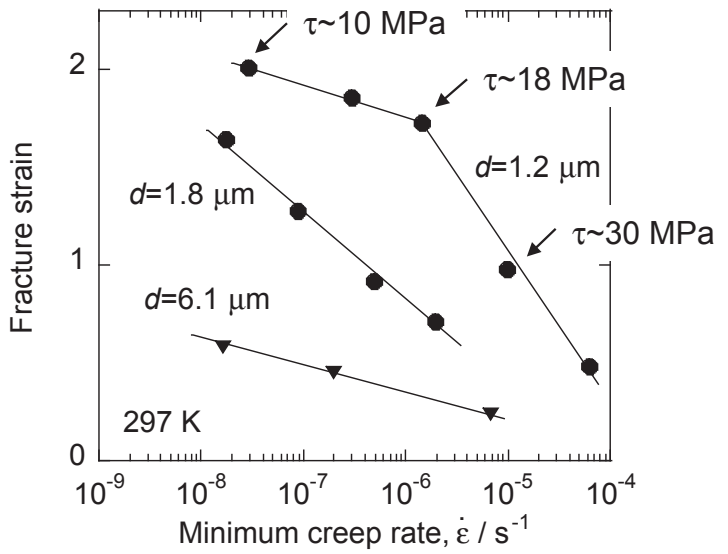

Fig. 6 Relation between fracture strain and minimum creep rate for all samples. The lower the minimum creep rate becomes, the greater failure strain becomes.

as shown in Fig. 6. The result might be affected by the activation of deformation twin. CRSS of $\{10 \overline{1} 2\}$ twin, the non-basal slip systems, and $\{10 \overline{1} 1\}$ twin were $6.9 \mathrm{MPa},{ }^{12)}$ 35.7 MPa, ${ }^{1)}$ 76-153 $\mathrm{MPa},{ }^{13,14)}$ respectively. Because higher shear stress, i.e., $\tau=\sigma / M>27 \mathrm{MPa}$, was needed for the sample with $d=6.1 \mu \mathrm{m},\{10 \overline{1} 2\}$ twin and non-basal slip systems were activated. On the other hand, the sample with $d=1.2 \mu \mathrm{m}$ showed the creep behavior and the large fracture strain at $\tau>8 \mathrm{MPa}$. Because twin nucleation is suppressed in a fine-grained $\mathrm{Mg}$ alloy, ${ }^{15)}$ only basal slip leads to low workhardening, generating the creep behavior. Next, the fracture strain decreased drastically at $\tau>30 \mathrm{MPa}$ in the sample with $d=1.2 \mu \mathrm{m}$ (see Fig. 6). The shear stress corresponded to CRSS of non-basal slip systems. It means multi slip systems are activated in the sample at high stress. Therefore, the high stress might result from high work-hardening, consequently decreasing fracture strain.

To verify the discussion presented above, fractography and EBSD analyses were conducted after creep tests. Specimens were $(\mathrm{a}-\mathrm{c})$ the sample with $d=1.2 \mu \mathrm{m}$ crept at $\sigma=30 \mathrm{MPa}$, (d-f) the sample with $d=1.2 \mu \mathrm{m}$ crept at $\sigma=130 \mathrm{MPa}$, and (g-i) the sample with $d=6.1 \mu \mathrm{m}$ crept at $\sigma=150 \mathrm{MPa}$. Although the fine-grained samples showed dimples clearly after both creep tests, the dimples were shallower in higherstress test. EBSD analyses showed that deformation twin was slightly observed in the crept samples with $d=1.2 \mu \mathrm{m}$ (Fig. 7(c), (f)). Ghadeli et al. observed that the number of twins per unit area depends on the grain size for pure $\mathrm{Mg}$ with $d=5.1-55 \mu \mathrm{m}^{16)}$ Tsai et al. concluded that large grains are more easily twinned than small grains for a $\mathrm{Mg}-\mathrm{Al}-\mathrm{Zn}$ alloy. ${ }^{17)}$ Therefore, twin nucleation doesn't affect the creep at room temperature in the sample with $d=1.2 \mu \mathrm{m}$.

The sample crept at $\sigma=130 \mathrm{MPa}$ contained coarse grains near the fracture surface (Fig. 7(f)). Although fine-grains existed at boundaries, the grains were partially coarsened with few misorientation. At the stress, the fracture strain was about one-fifth of that at $\sigma=30 \mathrm{MPa}$. According to the above discussion related to Fig. 5, the fine grains showed easy grain boundary sliding with $Q=65 \mathrm{~kJ} / \mathrm{mol}$. However, the concomitant phenomena might change according to the applied creep stress. At low stress, the creep rate can correspond to dislocation absorption and its nucleation rates 

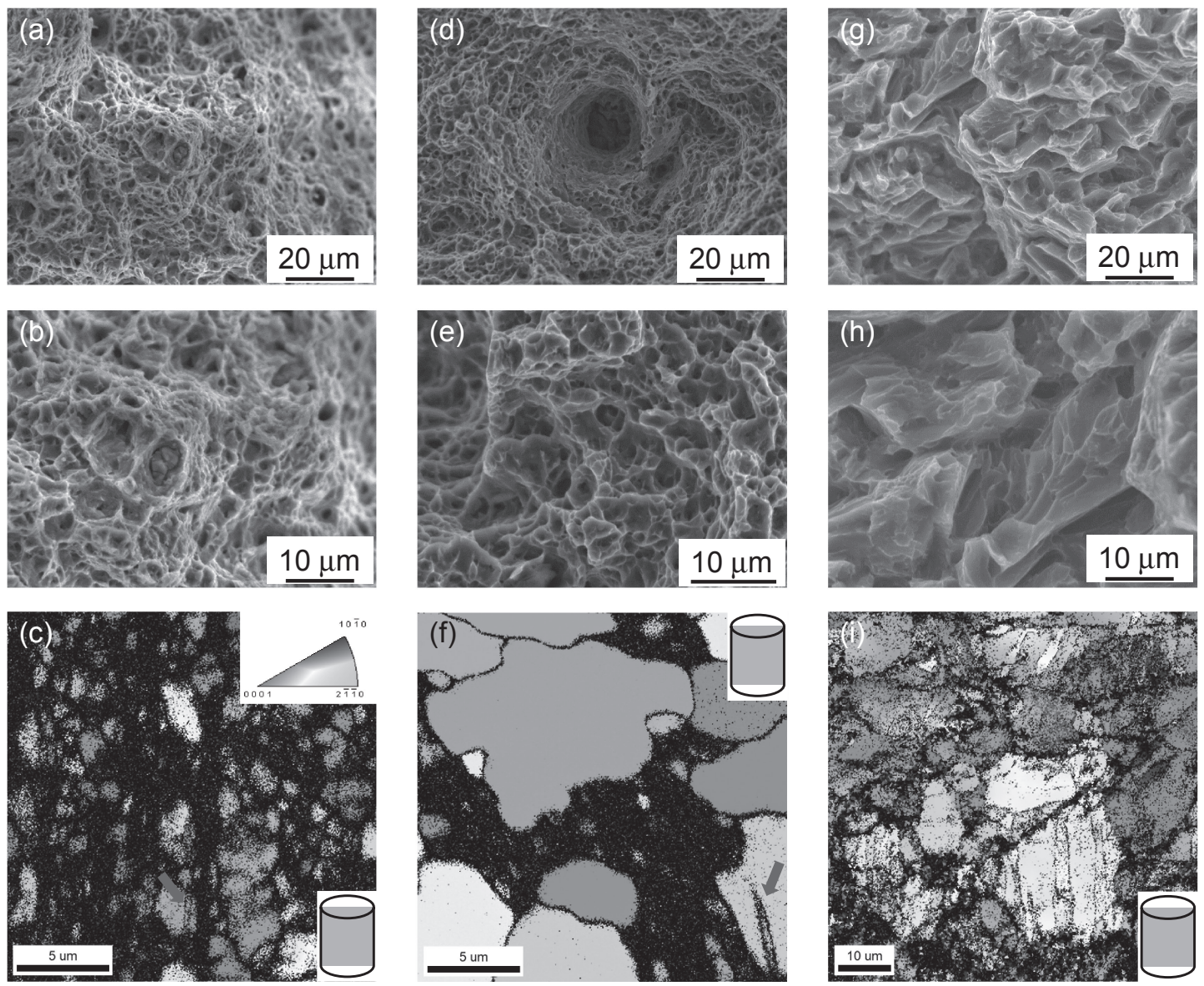

Fig. 7 Fractographs taken after creep tests and IPF maps of the near fracture surface of (a)-(c) the sample with $d=1.2 \mu \mathrm{m}$ crept at $30 \mathrm{MPa},(\mathrm{d})-(\mathrm{f})$ the sample with $d=1.2 \mu \mathrm{m}$ crept at $130 \mathrm{MPa}$, and (g)-(i) the sample with $d=6.1 \mu \mathrm{m}$ crept at $150 \mathrm{MPa}$. In these maps, data with low coincident index value are ignored.

at grain boundaries. Therefore, the strain compatibility is maintained during deformation, leading to the large fracture strain. However, the high stress of $\sigma=130 \mathrm{MPa}$, generated the high creep rate, which is about 40 times higher than that at $\sigma=30 \mathrm{MPa}$. The rate might not accommodate stored creep strain partially at grain boundaries, resulting in local strain accumulation there. Reportedly, $\mathrm{Mg}$ alloys show dynamic recrystallization (DRX) during warm deformation at around $500 \mathrm{~K}^{18,19)}$ For these alloys, the DRX site was grain boundaries because of boundary migration ${ }^{18)}$ and lattice rotation around boundaries. ${ }^{19)}$ The results support our assumption that grain boundaries are recrystallization sites for the sample with $d=1.2 \mu \mathrm{m}$ during the creep test. In addition, Galiyev et al. reported DRX results from twin, basal, and non-basal slips. ${ }^{20)}$ At $\sigma=130 \mathrm{MPa}$, i.e., $\tau=$ $43 \mathrm{MPa}$, these mechanisms were activated. Therefore, high stress and high strain rate might restrict deformable area and engender DRX at grain boundaries. The phenomena suppressed easy grain boundary sliding, generating the low fracture strain at high stress.

In addition, much shallower dimples were observed in the sample with $d=6.1 \mu \mathrm{m}$, which contains highly dense twins near the fracture surface (Fig. 7(i)). Although some data points showed low coincident index values, EBSD analyses show that coarse grain leads to twin nucleation obviously during creep, generating low ductility in pure $\mathrm{Mg}$. Similar behavior was observed after room temperature creep tests in AZ31. ${ }^{21)}$ In addition, twin nucleation might decrease fracture strain because the twin becomes a crack site. ${ }^{22)}$ Therefore, fine grains generate non-diffusional grain boundary sliding and less twin nucleation, leading to large fracture strain at low stress, whereas high stress restricts grain boundary sliding. Consequently, the fracture strain decreases. Coarse grains are nucleation sites of numerous twin during creep, leading to low fracture strain.

\section{Conclusions}

Creep tests and conventional tensile tests were performed to elucidate the mechanisms of low homologous temperature creep in pure $\mathrm{Mg}$ with $d=1.2 \mu \mathrm{m}, 1.8 \mu \mathrm{m}$, and $6.1 \mu \mathrm{m}$. The sample with $d=1.2 \mu \mathrm{m}$ showed especially large rupture strain of $>170 \%$ under creep conditions. The behavior included threshold stress related to the Frank-Read source, along with slip-induced grain-boundary sliding with $Q=$ $65 \mathrm{~kJ} / \mathrm{mol}$, which is only $70 \%$ of that of grain-boundary diffusion at room temperature. However, the sample with $d=6.1 \mu \mathrm{m}$ or high-stress creep tests showed small amount of fracture strain because of twin nucleation during creep tests. Therefore, preventing deformation twin by grain refinement leads to large rupture strain and decrease of creep resistance at low stress and low homologous temperatures in $\mathrm{Mg}$. 


\section{REFERENCES}

1) M. Arul Kumar, A.K. Kanjarla, S.R. Niezgoda, R.A. Lebensohn and C.N. Tomé: Acta Mater. 84 (2015) 349-358.

2) M. Mabuchi, K. Ameyama, H. Iwasaki and K. Higashi: Acta Mater. 47 (1999) 2047-2057.

3) Y.H. Wei, Q.D. Wang, Y.P. Zhu, H.T. Zhou, W.J. Ding, Y. Chino and M. Mabuchi: Mater. Sci. Eng. A 360 (2003) 107-115.

4) V.N. Chuvil'deev, T.G. Nieh, M.Yu. Gryaznov, A.N. Sysoev and V.I. Kopylov: Scr. Mater. 50 (2004) 861-865.

5) H.J. Frost and M.F. Ashby: Deformation Mechanism Maps: The Plasticity and Creep of Materials, (Pergamon Press, Oxford, 1982) pp. 44-52.

6) M. Kato, T. Fujii and S. Onaka: Mater. Trans. 49 (2008) 1278-1283.

7) C.H. Cáceres and P. Lukáč: Philos. Mag. 88 (2008) 977-989.

8) H. Somekawa and T. Mukai: Metall. Mater. Trans. A 46 (2015) 894 902.

9) J. Koike, R. Ohyama, T. Kobayashi, M. Suzuki and K. Maruyama: Mater. Trans. 44 (2003) 445-451.
10) A. Ball and M.M. Hutchison: Met. Sci. J. 3 (1969) 1-7.

11) T. Zhu, J. Li, A. Samanta, A. Leach and K. Gall: Phys. Rev. Lett. 100 (2008) 025502.

12) E.W. Kelly and W.F. Hosford, Jr.: Trans. TMS-AIME. 242 (1968) 513.

13) R.E. Reed-Hill and W.D. Robertson: Acta Metall. 5 (1957) 728-737.

14) H. Yoshinaga and R. Horiuchi: Trans. JIM 4 (1963) 1-8.

15) Q. Yang and A.K. Ghosh: Acta Mater. 54 (2006) 5159-5170.

16) A. Ghaderi and M.R. Barnett: Acta Mater. 59 (2011) 7824-7839

17) M.S. Tsai and C.P. Chang: Mater. Sci. Technol. 29 (2013) 759-763.

18) X. Yang, H. Miura and T. Sakai: Mater. Trans. 44 (2003) 197-203.

19) S.E. Ion, F.J. Humphreys and S.H. White: Acta Metall. 30 (1982) 1909-1919.

20) A. Galiyev, R. Kaibyshev and G. Gottstein: Acta Mater. 49 (2001) 1199-1207.

21) T. Matsunaga, H. Somekawa, H. Hongo and M. Tabuchi: Mater. Sci. Eng. A 647 (2015) 212-215.

22) D. Ando, J. Koike and Y. Sutou: Mater. Sci. Eng. A 600 (2014) 145152. 